\title{
Electrochemical Behaviour of Actinides and Fission Products in Room-Temperature Ionic Liquids
}

\author{
K. A. Venkatesan, Ch. Jagadeeswara Rao, K. Nagarajan, and P. R. Vasudeva Rao \\ Fuel Chemistry Division, Indira Gandhi Centre for Atomic Research, Kalpakkam 603 102, India \\ Correspondence should be addressed to K. A. Venkatesan, kavenkat@igcar.gov.in
}

Received 20 April 2011; Accepted 6 September 2011

Academic Editor: Oliver Höfft

Copyright ( $\odot 2012$ K. A. Venkatesan et al. This is an open access article distributed under the Creative Commons Attribution License, which permits unrestricted use, distribution, and reproduction in any medium, provided the original work is properly cited.

\begin{abstract}
In the recent past, room-temperature ionic liquids (RTILs) are being explored for possible applications in nuclear fuel cycle. RTILs are being studied as an alternative to the diluent, n-dodecane (n-DD), in aqueous reprocessing and as possible substitute to hightemperature molten salts in nonaqueous reprocessing applications. This paper deals with the current status of the electrochemical research aimed at the recovery of actinides and fission products using room-temperature ionic liquid as medium. The dissolution of actinide and lanthanide oxides in ionic liquid media and the electrochemical behavior of the resultant solutions are discussed in this paper.
\end{abstract}

\section{Introduction}

Nuclear reactors employ natural or enriched uranium as the fuel [1]. The spent nuclear fuel discharged from the nuclear reactor is composed of fissile elements such as plutonium and depleted uranium and several other elements formed by fission reaction, known as fission products. The spent nuclear fuel is, therefore, reprocessed to recover these fissile elements for the fabrication of nuclear fuel for future reactors. There are two different technologically viable methods available for reprocessing of spent nuclear fuel. The first one is the aqueous-based, industrially well-established, PUREX (plutonium uranium recovery by extraction) process [2] and the other is nonaqueous-based pyrochemical process [3]. The PUREX process involves the dissolution of spent nuclear fuel in nitric acid medium followed by the selective extraction of uranium and plutonium in a solution of trin-butylphosphate (TBP) in n-dodecane (DD). However, the undesirable limitation of the PUREX process is the chemical and radiolytic degradation of the solvent system and the generation of large volumes of secondary wastes. The flammability of hydrocarbon employed in the PUREX process is also another disadvantage.

In contrast to this method, the nonaqueous pyrochemical method for reprocessing of spent nuclear fuel has several advantages, such as minimum waste generation, low criticality concern and feasibility to reprocess the high burn-up, and short cooled fuels. This method exploits the differences in the thermodynamic stabilities of various actinides and fission products for the dissolution of spent nuclear fuel in the inorganic molten salt media followed by the electrochemical recovery of actinides [4]. Usually, the inorganic molten salt is composed of an eutectic of alkali or alkaline earth chloride. Therefore, the processing temperature in this method is invariably above $800 \mathrm{~K}$ depending upon the composition of chosen eutectic. In view of this, the pyrochemical method also offers a few challenges with respect to the plant design, requirement of inert atmosphere, high-temperature operation and corrosion problems, and so forth.

\section{Room-Temperature Ionic Liquids}

Substitution of unsymmetrical organic cation in place of alkali metal cation of the inorganic chloride salt dramatically reduces the melting point of the resultant organic chloride to near ambient temperatures. For instance, the melting temperature of $\mathrm{NaCl}$ is $1074 \mathrm{~K}$ and that of 1-butyl3-methylimidazolium chloride (bmimCl) is $343 \mathrm{~K}$. Such organic salts are known as room-temperature ionic liquids (RTILs). According to the most accepted definition, RTILs 
TABLE 1: Some of the cations and anions used to form room-temperature ionic liquids.

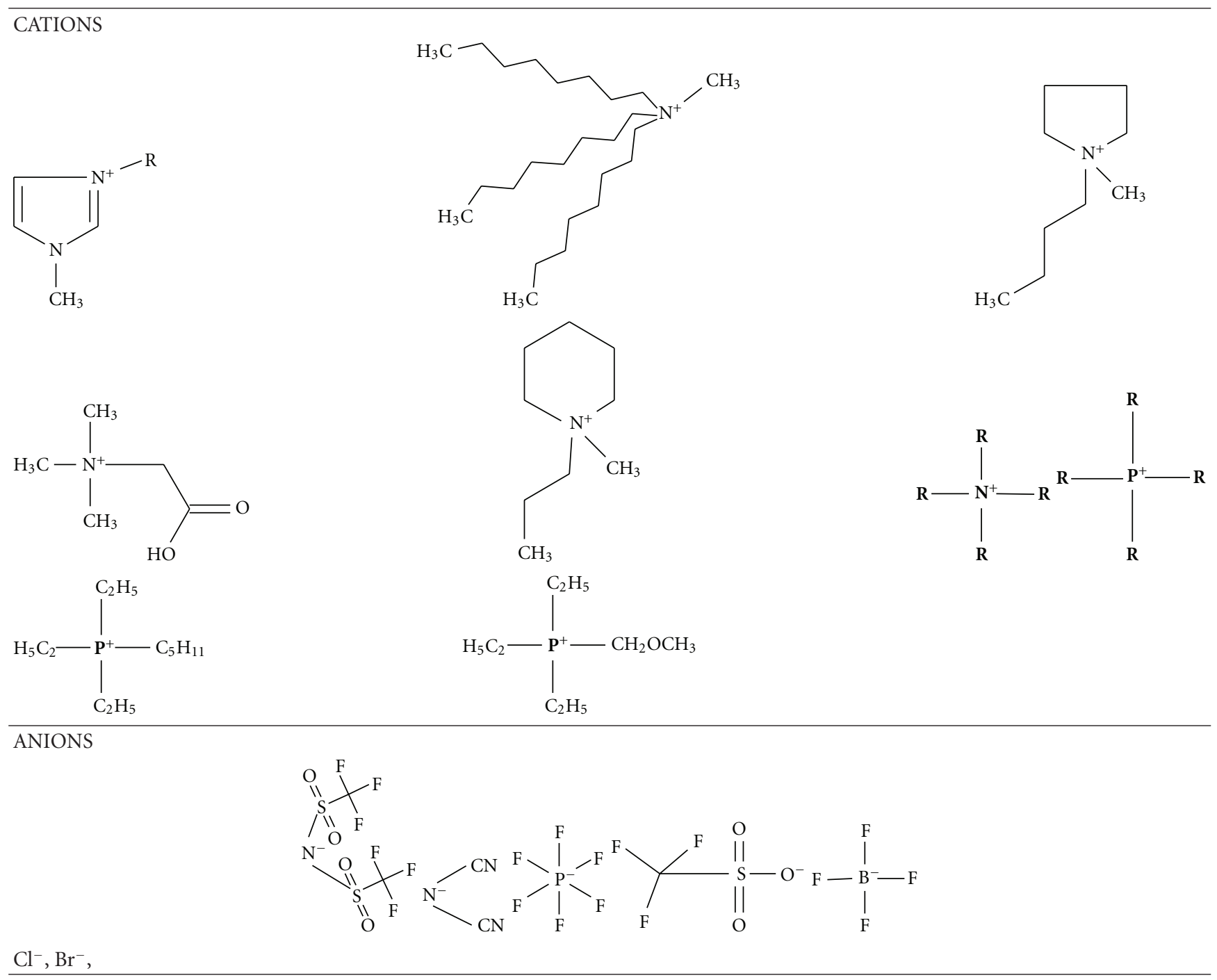

are composed fully of dissociated ions and melt at temperature lower than $373 \mathrm{~K} \mathrm{[5-7].} \mathrm{Some} \mathrm{examples} \mathrm{of} \mathrm{the} \mathrm{cation-}$ anion combinations for making RTILs are shown in Table 1. They have several attractive properties suitable for industrial exploitation such as insignificant vapour pressure, large liquidus range, good electrical conductivity and thermal stability, wide electrochemical window, and amazing ability to dissolve organic and inorganic compounds In view of this, RTILs are being explored for various applications [7-13].

\section{Electrochemical Stability of RTILs}

In the recent past, room-temperature ionic liquids are receiving increased attention for possible electrochemical applications in the area of nuclear fuel reprocessing and waste management. For such applications, it is desirable to use an ionic liquid that has good solubility of actinides, excellent thermal and radiation stability, and wide electrochemical window with extended cathodic stability. The knowledge of electrochemical stability can be derived from the measurement of the electrochemical window of RTIL. The electrochemical window $[7,14,15]$ is defined as the potential range in which the ionic liquid does not undergo any oxidation and reduction reactions. Table 2 shows the electrochemical windows of some ionic liquids offering electrochemical window more than $2 \mathrm{~V}$. The abbreviations of the ionic liquids reported are tabulated in Table 3. It is observed that many RTILs offer cathodic stability up to $-3.3 \mathrm{~V}$ and electrochemical window $>4 \mathrm{~V}$. Some RTILs offer window more than $6 \mathrm{~V}$, which is indeed desirable for the electrodeposition of metals such as lithium. Simka et al. [16] reviewed the electrodeposition of highly electropositive metals in ionic liquid media and reported the feasibility of using ionic liquids for such applications. Table 4 summarises the list of metals for which electrodeposition has been reported from RTIL medium $[16,17]$. It is observed that several metals ranging from S- block to P- block through the transition metals have been studied. However, the studies related to 
TABLE 2: The electrochemical windows of some ionic liquids GC-glassy carbon, VC- vitreous carbon, RDE-rotating disc electrode, and Fc-ferrocene.

\begin{tabular}{|c|c|c|c|c|c|}
\hline $\begin{array}{l}\text { Name of the ionic } \\
\text { liquid }\end{array}$ & $\begin{array}{l}\text { Cathodic } \\
\text { limit, V }\end{array}$ & $\begin{array}{l}\text { Anodic } \\
\text { limit, V }\end{array}$ & $\begin{array}{l}\text { Electrochemical window, } \mathrm{V} \\
\text { (reference electrode) }\end{array}$ & $\begin{array}{l}\text { Working } \\
\text { electrode }\end{array}$ & References \\
\hline \multirow[t]{2}{*}{ bmimCl } & -1.38 & 0.74 & $2.12(\mathrm{Pd})$ & GC & [18] \\
\hline & -2.2 & 2.2 & $4.4(\mathrm{Ag})$ & GC & [19] \\
\hline \multirow[t]{3}{*}{$\mathrm{bmimBF}_{4}$} & -2.2 & 2.4 & $4.6(\mathrm{Ag})$ & $\mathrm{Au}$ & [19] \\
\hline & -2.4 & 2.5 & $4.9(\mathrm{Ag})$ & $\mathrm{Pt}$ & [19] \\
\hline & -2.1 & +2.5 & 4.6 (SCE) & - & {$[8]$} \\
\hline \multirow[t]{2}{*}{$\mathrm{bmimPF}_{6}$} & -2.50 & 3.85 & $6.35(\mathrm{Pt})$ & VC RDE & [20] \\
\hline & -2.1 & $>5.0$ & $>7.1(\mathrm{Pt})$ & W RDE & [20] \\
\hline $\operatorname{bmimNTf}_{2}$ & $\sim-1.9$ & $\sim 2.3$ & $4.2(\mathrm{Ag})$ & $\mathrm{Pt}$ & [21] \\
\hline $\operatorname{bmimCF}{ }_{3} \mathrm{CO}_{2}$ & $\sim-2.0$ & $\sim 0.7$ & $2.7(\mathrm{SCE})$ & - & {$[8]$} \\
\hline \multirow[t]{2}{*}{ hmimCl } & -0.88 & 0.75 & $1.63(\mathrm{Pd})$ & GC & [22] \\
\hline & -1.8 & 2.4 & $4.2(\mathrm{Ag})$ & GC & [19] \\
\hline \multirow{3}{*}{$\mathrm{bdmimBF}_{4}$} & -2.3 & 2.3 & $4.6(\mathrm{Ag})$ & $\mathrm{Au}$ & [19] \\
\hline & -2.0 & 2.3 & $4.3(\mathrm{Ag})$ & $\mathrm{Pt}$ & [19] \\
\hline & -2.4 & 3.0 & $5.4(\mathrm{Ag})$ & $\mathrm{Ta}$ & [19] \\
\hline \multirow[t]{2}{*}{ HbetNTf $_{2}$} & -1.16 & 1.2 & $2.4\left(\mathrm{Fc} / \mathrm{Fc}^{+}\right)$ & GC & [23] \\
\hline & -2.91 & 2.65 & $5.56\left(\mathrm{Fc} / \mathrm{Fc}^{+}\right)$ & GC & {$[22,24]$} \\
\hline \multirow[t]{2}{*}{$\mathrm{BMPyNTf}_{2}$} & $\sim-3.1$ & $\sim 3.2$ & $6.3(\mathrm{Pt})$ & GC & {$[25]$} \\
\hline & -3.0 & 2.5 & $5.5\left(\mathrm{Ag} / \mathrm{Ag}^{+}\right)$ & GC & [26] \\
\hline \multirow{2}{*}{ MPPiNTf $_{2}$} & -2.71 & 2.26 & $4.97\left(\mathrm{Fc} / \mathrm{Fc}^{+}\right)$ & GC & [22] \\
\hline & -3.3 & 2.3 & $5.6\left(\mathrm{Fc} / \mathrm{Fc}^{+}\right)$ & GC & [27] \\
\hline $\mathrm{P}_{2225} \mathrm{DCA}$ & $\sim-3.2$ & $\sim 2.6$ & $5.8\left(\mathrm{Ag} / \mathrm{Ag}^{+}\right)$ & $\mathrm{Pt}$ & [28] \\
\hline $\mathrm{P}_{222(101)} \mathrm{DCA}$ & $\sim-2.5$ & $\sim 3.0$ & $5.5\left(\mathrm{Ag} / \mathrm{Ag}^{+}\right)$ & $\mathrm{Pt}$ & [28] \\
\hline $\mathrm{N}_{222(101)} \mathrm{DCA}$ & $\sim-2.6$ & $\sim 2.4$ & $5.0\left(\mathrm{Ag} / \mathrm{Ag}^{+}\right)$ & $\mathrm{Pt}$ & [28] \\
\hline $\mathrm{P}_{222(201)} \mathrm{DCA}$ & $\sim-2.5$ & $\sim 2.6$ & $5.1\left(\mathrm{Ag} / \mathrm{Ag}^{+}\right)$ & $\mathrm{Pt}$ & [28] \\
\hline $\mathrm{P}_{2225} \mathrm{NTf}_{2}$ & $\sim-3.2$ & $\sim 3.0$ & $6.2(\mathrm{Fc} / \mathrm{Fc}+)$ & $\mathrm{Pt}$ & [29] \\
\hline $\mathrm{P}_{222(101)} \mathrm{NTf}_{2}$ & $\sim-3.0$ & $\sim 2.7$ & $5.7\left(\mathrm{Fc} / \mathrm{Fc}^{+}\right)$ & $\mathrm{Pt}$ & [29] \\
\hline $\mathrm{P}_{2228} \mathrm{NTf}_{2}$ & $\sim-3.2$ & $\sim 3.0$ & $6.2\left(\mathrm{Fc} / \mathrm{Fc}^{+}\right)$ & $\mathrm{Pt}$ & [29] \\
\hline $\mathrm{P}_{222(201)} \mathrm{NTf}_{2}$ & $\sim-3.1$ & $\sim 2.2$ & $5.3\left(\mathrm{Fc} / \mathrm{Fc}^{+}\right)$ & $\mathrm{Pt}$ & [29] \\
\hline $\operatorname{bmim}\left(\mathrm{CF}_{3}\right)_{2} \mathrm{PO}_{2}$ & $\sim-2.3$ & $\sim 2.2$ & $4.5(\mathrm{Ag})$ & $\mathrm{Pt}$ & [21] \\
\hline bmimOTf & $\sim-2.2$ & $\sim 2.8$ & $5.0(\mathrm{Pt})$ & GC & [25] \\
\hline \multirow{2}{*}{$\mathrm{emimBF}_{4}$} & $\sim-2.1$ & $\sim 1.9$ & $4.0(\mathrm{Pt})$ & GC & [25] \\
\hline & $\sim 0.9$ & $\sim 5.0$ & $4.1\left(\mathrm{Li} / \mathrm{Li}^{+}\right)$ & GC & [30] \\
\hline $\operatorname{mpimBF}_{4}$ & $\sim 1.0$ & $\sim 5.1$ & $4.1\left(\mathrm{Li} / \mathrm{Li}^{+}\right)$ & GC & {$[30]$} \\
\hline $\mathrm{Bu}_{4} \mathrm{NNO}_{3}$ & $\sim-3.0$ & $\sim 1.5$ & 4.5 (SCE) & - & [8] \\
\hline $\mathrm{Bu}_{4} \mathrm{PNO}_{3}$ & $\sim-2.0$ & $\sim 1.5$ & 3.5 (SCE) & - & {$[8]$} \\
\hline
\end{tabular}

lanthanides and actinides are less. In addition, the metallic electrodeposit obtained for lanthanides are not usually stable and undergoes oxidation to their respective oxides during electrolysis.

\section{Electrochemical Behavior of Lanthanides and Actinides in Ionic Liquids}

The electrochemistry of actinides was indeed reported a few decades ago using chloroaluminate-based RTIL as the medium. However, these studies were not directed towards the electrodeposition of actinides, but involved only the basic understanding of coordination chemistry, solution chemistry, and electrochemical behaviour of metals. In fact, this was due to the inadequacy in the electrochemical window and poor cathodic stability of chloroaluminates. The earliest work on the electrochemistry of uranium in acidic and basic chloroaluminate melt was reported by D'Olieslanger and coworkers $[31,32]$. In acidic 2:1 melts $\left(\mathrm{AlCl}_{3}: \mathrm{N}\right.$-(n-butyl) pyridinium chloride), the reduction of $\mathrm{U}(\mathrm{IV})$ to $\mathrm{U}(\mathrm{III})$ at glassy carbon electrodes was reported to be irreversible. The formal standard potential of the $\mathrm{U}(\mathrm{IV}) / \mathrm{U}(\mathrm{III})$ redox couple as a function of the melt acidity was determined. $\mathrm{U}(\mathrm{III})$ in the melt was found to exist as 
TABle 3: The abbreviations of the ionic liquids.

\begin{tabular}{|c|c|}
\hline Name of the ionic liquid & Abbreviation \\
\hline 1-butyl-3-methylimidazolium chloride & bmimCl \\
\hline 1-butyl-3-methylimidazolium tetrafluoroborate & $\mathrm{bmimBF}_{4}$ \\
\hline 1-butyl-3-methylimidazolium hexafluorophosphate & bmimPF$_{6}$ \\
\hline 1-butyl-3-methylimidazolium bis(trifluoromethanesulfonyl)imide & $\operatorname{bmimNTf}_{2}$ \\
\hline 1-butyl-3-methylimidazolium trifluoromethanecarbonate & $\mathrm{bmimCF}_{3} \mathrm{CO}_{2}$ \\
\hline 1-butyl-3-methylimidazolium dicyanamide & bmimDCA \\
\hline 1-hexyl-3-methylimidazolium chloride & $\mathrm{hmimCl}$ \\
\hline 1-butyl-2,3-dimethylimidazolium chloride & $\mathrm{bdmimBF}_{4}$ \\
\hline Betaine bis(trifluoromethanesulfonyl)imide & HbetNTf $_{2}$ \\
\hline N-butyl-N-methylpyrrolidinium bis(trifluoromethanesulfonyl)imide & $\mathrm{BMPyNTf}_{2}$ \\
\hline N-methyl-N-propylpiperidinium bis(trifluoromethanesulfonyl)imide & $\mathrm{MPPiNTf}_{2}$ \\
\hline Triethylpentylphosphonium dicyanamide & $\mathrm{P}_{2225} \mathrm{DCA}$ \\
\hline Triethyldimethyletherphosphonium dicyanamide & $\mathrm{P}_{222(101)} \mathrm{DCA}$ \\
\hline Triethyldimethyletherammonium dicyanamide & $\mathrm{N}_{222(101)} \mathrm{DCA}$ \\
\hline Triethylethylmethyletherphosphonium dicyanamide & $\mathrm{P}_{222(201)} \mathrm{DCA}$ \\
\hline Triethylpentylphosphonium bis(trifluoromethanesulfonyl)imide & $\mathrm{P}_{2225} \mathrm{NTf}_{2}$ \\
\hline Triethyldimethyletherphosphonium bis(trifluoromethanesulfonyl)imide & $\mathrm{P}_{222(101)} \mathrm{NTf}_{2}$ \\
\hline Triethyloctylphosphonium bis(trifluoromethanesulfonyl)imide & $\mathrm{P}_{2228} \mathrm{NTf}_{2}$ \\
\hline Triethylethylmethyletherphosphonium bis(trifluoromethanesulfonyl)imide & $\mathrm{P}_{222(201)} \mathrm{NTf}_{2}$ \\
\hline 1-butyl-3-methylimidazolium bis(trifluoromethane)phosphinate & $\operatorname{bmim}\left(\mathrm{CF}_{3}\right)_{2} \mathrm{PO}_{2}$ \\
\hline 1-butyl-3-methylimidazolium bis(trifluoromethane)sulfonate & bmimOTf \\
\hline 1-ethyl-3-methylimidazolium chloride & emimCl \\
\hline 1-ethyl-3-methylimidazolium tetrafluoroborate & $\mathrm{emimBF}_{4}$ \\
\hline 1-ethyl-3-methylimidazolium bis(trifluoromethanesulfonyl)imide & $\operatorname{emimNTf}_{2}$ \\
\hline 1-methyl-3-propylimidazolium tetrafluoroborate & $\mathrm{mpimBF}_{4}$ \\
\hline Tetrabutylammonium nitrate & $\mathrm{Bu}_{4} \mathrm{NNO}_{3}$ \\
\hline Tetrabutylphosphonium nitrate & $\mathrm{Bu}_{4} \mathrm{PNO}_{3}$ \\
\hline Tri-n-butylmethyl ammonium bis(trifluoromethanesulfonyl)imide & $\mathrm{Bu}_{3} \mathrm{mebu}_{3} \mathrm{NNTf}_{2}$ \\
\hline Tri-n-methylbutyl ammonium bis(trifluoromethanesulfonyl)imide & $\mathrm{Me}_{3} \mathrm{NBuNTf}_{2}$ \\
\hline 1-octyl-1-methylpyrrolidinium bis(trifluoromethanesulfonyl)imide & $\mathrm{OMPyNTf}_{2}$ \\
\hline N,N-diethyl-N-methyl-N-(2-methoxyethyl)ammonium bis(trifluoromethanesulfonyl)imide & demmaNTf $_{2}$ \\
\hline Tricaprylmethylammonium nitrate & TOMAN \\
\hline 1-butylpyridinium chloride & $\mathrm{BuPyCl}$ \\
\hline 1-butylpyridinium tetrafluoroborate & $\mathrm{BuPyBF}_{4}$ \\
\hline Tricaprylmethylammonium chloride & Aliquat 336 \\
\hline 1-butyl-3-methylimidazolium nonafluorobutanesulfonate & BmimNfO \\
\hline 1-[2-(2-methoxyethoxy)ethyl]-3-methylimidazolium chloride & $\mathrm{C}_{5} \mathrm{O}_{2} \mathrm{ImCl}$ \\
\hline 1-[2-(2-methoxyethoxy)ethyl]-3-methylimidazolium hexafluorophosphate & $\mathrm{C}_{5} \mathrm{O}_{2} \mathrm{ImPF}_{6}$ \\
\hline
\end{tabular}

TABLE 4: List of some metals studied for the electrodeposition from room-temperature ionic liquid medium [16, 17].

\begin{tabular}{lll}
\hline S. No. & \multicolumn{1}{c}{ Group } & Metals deposited \\
\hline 1 & S-block elements & Li, Mg, Cs, and Sr \\
2 & P-block elements & Sn, Al, Al-In, Al-Sb, Al-In-Sb, Al-Si, Ge, Ga, Te, Tl, Pb, Bi, and Si \\
& & Ti, Ta, Mn, Zn, Zn-Mn alloy, Ru, Rh, Pd, Ag, Au, Co, Co-Zn \\
3 & Transition elements & alloy, Pd-Ag alloy, Pt-Zn alloy, Pt, Pd-In alloy, Ni-Zn alloy, \\
& Ni, Zn-Sn alloy, Cd-Te, Cu, Fe, Hg, Cr, and Nb \\
4 & Lanthanides & La, Eu, Nd, and Sm \\
5 & Actinides & $\mathrm{U}$ and Th \\
\hline
\end{tabular}


free $\mathrm{U}^{3+}$ ion, and $\mathrm{U}(\mathrm{IV})$ as chlorocomplexes, $\mathrm{UCl}_{x}{ }^{(4-x)+}$ with $3 \geq x \geq 1$. The oxidation of $\mathrm{U}(\mathrm{IV})$ to $\mathrm{U}(\mathrm{V})$ at glassy carbon electrodes was irreversible and dependent on the melt acidity. Further oxidation of $U(V)$ to $U(V I)$ was not feasible due to the anodic instability of the melt. In contrast to acidic melt, $\mathrm{U}(\mathrm{VI})$ in basic melt [33] $\left(\mathrm{AlCl}_{3}+\mathrm{BuPyCl}\right)$, existed as chloro complexes $\mathrm{UO}_{2} \mathrm{Cl}_{4+x}{ }^{(2+x)-}$, which underwent a singlestep irreversible two-electron transfer to soluble $\mathrm{UCl}_{6}{ }^{2-}$ as shown in (1). The diffusion coefficient was determined to be $2.65 \times 10^{-7} \mathrm{~cm}^{2} / \mathrm{s}$ in the basic melt (mole ratio of $\left.\mathrm{AlCl}_{3}: \mathrm{BuPyCl}=0.82: 1\right)$

$$
\begin{aligned}
{\left[\mathrm{UO}_{2} \mathrm{Cl}_{(4+x)}\right]^{(2+x)-}+2 \mathrm{AlCl}_{4}{ }^{-}+2 \mathrm{e}^{-} } \\
\longrightarrow \mathrm{UCl}_{6}{ }^{2-}+2 \mathrm{AlOCl}_{2}{ }^{-}+(2+x) \mathrm{Cl}^{-}
\end{aligned}
$$

In addition, $\mathrm{U}(\mathrm{IV})$ could not be reduced to $\mathrm{U}(\mathrm{III})$ in basic melt due to the cathodic instability of $\mathrm{BuPy}^{+}$cation, which undergoes reduction in preference to $\mathrm{U}(\mathrm{IV})$. However, $\mathrm{U}(\mathrm{VI})$ could be reduced to $\mathrm{U}(\mathrm{III})$ in basic $\mathrm{AlCl}_{3}$-emimCl [34, 35], as the 1-ethyl-3-methylimidazolium cation $\left(\mathrm{emim}^{+}\right)$ is more difficult to reduce than the $\mathrm{BuPy}^{+}$cation. The uranyl ion $\left(\mathrm{UO}_{2}{ }^{2+}\right)$ underwent a two electron transfer in basic $\mathrm{AlCl}_{3}$-emimCl melt followed by the transfer of oxygen to chloroaluminate complex of ionic liquid leading to the formation of $\left[\mathrm{UCl}_{6}\right]^{2-}$ as shown in (2) and (3). $\left[\mathrm{UCl}_{6}\right]^{2-}$ was then reduced to $\left[\mathrm{UCl}_{6}\right]^{3-}$ in the melt

$$
\begin{gathered}
{\left[\mathrm{UO}_{2} \mathrm{Cl}_{4}\right]^{2-}+2 \mathrm{AlCl}_{4}{ }^{-}+2 \mathrm{e}^{-}} \\
\longrightarrow 2\left\{\mathrm{AlOCl}_{2}\right\}^{-}+\left[\mathrm{UCl}_{6}\right]^{2-}+2 \mathrm{Cl}^{-} \\
{\left[\mathrm{UCl}_{6}\right]^{2-}+\mathrm{e}^{-} \longrightarrow\left[\mathrm{UCl}_{6}\right]^{3-}}
\end{gathered}
$$

Electrochemical behavior of $\mathrm{U}(\mathrm{VI})$ in bmimCl was reported by Giridhar et al. [18]. U(VI) in bmimCl underwent a single-step two-electron transfer reduction to uranium oxide $\left(\mathrm{UO}_{2}\right)$ deposit at glassy carbon working electrode. They reported that the electrochemical reduction was not only governed by the diffusion of U(VI), but also by charge transfer kinetics at the working electrode. Thermal analysis of the uranium oxide deposit obtained by the electrolysis of $\mathrm{U}(\mathrm{VI})$ from bmimCl revealed the entrapment of nearly $5 \%$ bmimCl during electrodeposition.

Ikeda and coworkers [36] developed a new approach for reprocessing spent nuclear fuel using room-temperature ionic liquid as medium. The method involved oxidative dissolution of the spent nuclear fuel by using $\mathrm{Cl}_{2}$, followed by the electrochemical reduction of $\mathrm{U}(\mathrm{VI})$ to $\mathrm{UO}_{2}$. By this method, the electrochemical behavior of $\mathrm{UO}_{2}{ }^{2+}$ in various ionic liquids such as bmimCl, bmimBF 4 , and bmimNfO was studied and the two-step reduction of $\mathrm{UO}_{2}{ }^{2+}$ to $\mathrm{U}(\mathrm{IV})$ through $\mathrm{U}(\mathrm{V})$ was reported. The electrochemical reduction of $\mathrm{UO}_{2}{ }^{2+}$ in bmimNfO at $-1.0 \mathrm{~V}$ (versus $\mathrm{Ag} / \mathrm{AgCl}$ ) produced uranium oxide deposit at carbon electrode. The electrochemical behaviour of $\left[\mathrm{UO}_{2} \mathrm{Cl}_{4}\right]^{2-}$ in bmimCl ionic liquid was also reported by Ikeda et al. [37]. The uranium complex, $\left[\mathrm{UO}_{2} \mathrm{Cl}_{4}\right]^{2-}$, was dissolved in bmimCl by using $\mathrm{Cs}_{2} \mathrm{UO}_{2} \mathrm{Cl}_{4}$ or $\mathrm{UO}_{2} \mathrm{Cl}_{2} \cdot \mathrm{nH}_{2} \mathrm{O}$ compounds and reported the quasireversible reduction of $\left[\mathrm{UO}_{2} \mathrm{Cl}_{4}\right]^{2-}$ to $\left[\mathrm{UO}_{2} \mathrm{Cl}_{4}\right]^{3-}$. Similarly, Ikeda and coauthors [38] studied the dissolution of uranium fluoride $\left(\mathrm{UF}_{4}\right)$ in bmimCl by oxidation of $\mathrm{U}(\mathrm{IV})$ to $\mathrm{U}(\mathrm{VI})$ and the $\mathrm{UO}_{2}{ }^{2+}$ present in bmimCl was reduced to $\mathrm{UO}_{2}$ by a two-step one electron transfer.

The electrochemical behaviour of neptunium in acidic and basic $\mathrm{AlCl}_{3}-1-n$-butylpyridinium chloride melt at $313 \mathrm{~K}$ was studied by Schoebrechts and Gilbert [39]. In acidic and basic melts, the reduction of $\mathrm{Np}(\mathrm{IV})$ to $\mathrm{Np}$ (III) at glassy carbon electrode was quasireversible. In basic melt, $\mathrm{Np}$ (III) and $\mathrm{Np}(\mathrm{IV})$ exist as $\mathrm{NpCl}_{6}{ }^{3-}$ and $\mathrm{NpCl}_{6}{ }^{2-}$, whereas in acidic melt it exist in the form of solvated $\mathrm{Np}^{3+}$ and $\mathrm{NpCl}_{x}{ }^{(4-x)-}(3 \geq x \geq 1)$. The study showed that the acidic melt acted as a poor solvating medium for neptunium.

Choppin and coworkers [40] have investigated the electrochemistry and spectroscopy of $\mathrm{UO}_{2}{ }^{2+}$ in acidic chloroaluminate medium. $\mathrm{UO}_{2}{ }^{2+}$ in acidic $\mathrm{AlCl}_{3}$-emimCl melt was gradually reduced to $\mathrm{U}(\mathrm{V})$ and it was facilitated only by $\mathrm{AlCl}_{4}{ }^{-}$and $\mathrm{Al}_{2} \mathrm{Cl}_{7}{ }^{-}$species by the sequence of reactions shown in the following:

$$
\begin{aligned}
& \mathrm{UO}_{2}{ }^{2+}+\mathrm{Al}_{2} \mathrm{Cl}_{7}{ }^{-} \longrightarrow \mathrm{UO}^{4+}+\mathrm{AlCl}_{4}{ }^{-}+\mathrm{AlOCl}_{3}{ }^{2-} \text {, } \\
& \mathrm{UO}^{4+}+\mathrm{Al}_{2} \mathrm{Cl}_{7}{ }^{2-} \longrightarrow \mathrm{U}^{6+}+\mathrm{AlCl}_{4}{ }^{-}+\mathrm{AlOCl}_{3}{ }^{2-} \text {, } \\
& \mathrm{U}^{6+}+\mathrm{AlCl}_{4}{ }^{-} \longrightarrow \mathrm{U}^{5+}+\mathrm{AlCl}_{3}+1 / 2 \mathrm{Cl}_{2} .
\end{aligned}
$$

Deetlefs et al. studied [41] the electrochemistry of various uranium halide complexes in basic and acidic bromoaluminate (III) imidazolium ionic liquid. U(IV) in the basic ionic liquid was reduced to $\mathrm{U}(\mathrm{III})$ and $\mathrm{U}(\mathrm{VI})$ to $\mathrm{U}(\mathrm{IV})$. Lin and Hussey [42] studied the electrochemical and spectroscopic properties of $\mathrm{Ce}(\mathrm{III})$ in basic $\mathrm{AlCl}_{3}$-emimCl and reported a quasireversible reduction of $\mathrm{Ce}(\mathrm{IV})$ to $\mathrm{Ce}$ (III) at glassy carbon, $\mathrm{Pt}$ and $\mathrm{W}$ electrodes.

The redox behavior of actinides in haloaluminate ionic liquids (1st generation) demonstrate that the electrochemical window of haloaluminates permits the redox conversion of $\mathrm{An}(\mathrm{III})$ to $\mathrm{An}(\mathrm{VI})$ and vice versa, irrespective of the composition of RTIL. Reduction of An(III) to An(0) was not feasible due to inadequate cathodic stability of haloaluminates. A similar behavior could be expected for lanthanides also, as the characteristic trivalents are hard to reduce to metallic state than actinides. The studies reported by Schoebrechts et al. $[43,44]$ also confirmed that some trivalent lanthanides ions such as $\mathrm{Sm}$ (III), $\mathrm{Eu}(\mathrm{III}), \mathrm{Tm}$ (III), and $\mathrm{Yb}$ (III) dissolved in acidic $\mathrm{AlCl}_{3}-\mathrm{BuPyCl}$ ionic liquid were reduced only to the corresponding divalent ions. Due to these limitations, RTILs did not gain popularity in nonaqueous reprocessing earlier.

Moisture stable ionic liquids were discovered in late 1990s. They are known as 2nd generation ionic liquids. Several RTILs having electrochemical window as large as $\sim 6 \mathrm{~V}$ and extended cathodic stability [45-47] were identified. This factor gave a renaissance to the use of ionic liquids in nonaqueous processing applications. Nikitenko and coworkers [48-50] investigated the spectroscopic and electrochemical aspects of U(IV)-hexachloro complexes in bmimNTf $2, \mathrm{Bu}_{3} \mathrm{MeNNTf}_{2}$ hydrophobic ionic liquids. Due to 
large electrochemical window of RTIL, it was possible to study the oxidation and reduction behaviour, up to the metallic form. The uranium redox values were reported depend strongly on the type of RTIL cation. $\left[\mathrm{UCl}_{4}\right]^{2-}$ in $\mathrm{Bu}_{3} \mathrm{MeNNTf}_{2}$ can be converted to metallic uranium at $-3.12 \mathrm{~V}$ (versus $\mathrm{Fc} / \mathrm{Fc}^{+}$) at $333 \mathrm{~K}$. Nikitenko and Moisy [50] further investigated the coordination behaviour of $\mathrm{Np}$ (IV) and $\mathrm{Pu}(\mathrm{IV})$ in bmimNTf${ }_{2}$. The $\left[\mathrm{NpCl}_{6}\right]^{2-}$ and $\left[\mathrm{PuCl}_{6}\right]^{2-}$ complexes are electrochemically inert in bmimNTf at $_{2}$ glassy carbon electrode. However, the addition of bmimCl facilitated the quasireversible electrochemical reduction of $\mathrm{Np}(\mathrm{IV}) / \mathrm{Np}(\mathrm{III})$ and $\mathrm{Pu}(\mathrm{IV}) / \mathrm{Pu}(\mathrm{III})$ and oxidation of $\mathrm{Np}$ (IV) and $\mathrm{Pu}(\mathrm{IV})$. These redox reactions were reported only when $\mathrm{Cl}^{-} / \mathrm{An}(\mathrm{IV})$ ratio exceeded six in ionic liquid medium.

Bhatt et al. [51-53] studied the electrochemistry of some lanthanide ions, $\mathrm{La}(\mathrm{III}), \mathrm{Sm}(\mathrm{III})$, and $\mathrm{Eu}(\mathrm{III})$ in $\mathrm{R}_{4} \mathrm{XNTf}_{2}$, where $\mathrm{X}=\mathrm{N}, \mathrm{P}$, and As. The RTIL, $\mathrm{Me}_{4} \mathrm{XNTf}$, exhibited a large electrochemical window $(\sim 6 \mathrm{~V})$. They also studied [52] the reduction of $\mathrm{La}$ (III), Sm(III), and $\mathrm{Eu}$ (III) to metallic state in the RTIL, $\mathrm{Me}_{3} \mathrm{BuNNTf}_{2}$, and reported similar results as in the previous case. However, it was reported that the deposits were not stable and underwent very fast oxidation to their respective oxides during the course of washing treatment. Moreover, the standard reduction potentials of these lanthanides are nearer or negative to the reduction potential of the ionic liquids. Therefore, the lanthanides electrodeposit obtained using these ionic liquids were not very useful. The voltammetric behavior of $\left[\mathrm{Th}\left(\mathrm{NTf}_{2}\right)_{4}\left(\mathrm{HNTf}_{2}\right)\right] \cdot 2 \mathrm{H}_{2} \mathrm{O}$ was also studied [53] in $\mathrm{Me}_{3} \mathrm{BuNNTf}_{2}$. Th(IV) in this ionic liquid was reduced to $\mathrm{Th}(0)$ by a single-step reduction. The $\mathrm{E}^{0}$ value for the reduction of $\mathrm{Th}(\mathrm{IV})$ to $\mathrm{Th}(0)$ was determined to be $-2.20 \mathrm{~V}$ (versus $\left(\mathrm{Fc}^{+} / \mathrm{Fc}\right),-1.80 \mathrm{~V}$ versus $\left.\mathrm{SHE}\right)$. Due to the presence of moisture in ionic liquid, the reduced product $\mathrm{Th}(0)$ was converted to $\mathrm{ThO}_{2}$.

Legeai et al. [54] reported the electrodeposition of lanthanum in $\mathrm{OMPyNTf}_{2}$ ionic liquid. The authors reported that the wide electrochemical window $(4.8 \mathrm{~V})$ and low hygroscopic character of $\mathrm{OMPyNTf}_{2}$ allowed the electrodeposition of lanthanum without the need of an inert atmosphere. About $350 \mathrm{~nm}$ thick lanthanum film on $\mathrm{Pt}$ electrode was deposited. Nagaishi et al. [55] studied the physicochemical behaviour, spectroscopic and electrochemical behavior of $\mathrm{Eu}(\mathrm{III})$ as a function of water in demmaNTf and bmimNTf $\mathrm{N}_{2}$ ionic liquids. The variations in the diffusion coefficient of Eu(III) in dehydrated and water saturated conditions were reported by the authors. Yamagata et al. [56] studied the electrochemical behaviour of samarium(III), europium(III) and ytterbium(III) in $\mathrm{BMPyNTf}_{2}$, and emimNTf ${ }_{2}$ ionic liquids. The quasireversible reduction of $\mathrm{Sm}(\mathrm{III}), \mathrm{Eu}(\mathrm{III})$ and $\mathrm{Yb}(\mathrm{III})$ to divalent state was reported. The electrochemical behaviour of Eu(III), Sm(III), and $\mathrm{Ce}(\mathrm{III})$ in bmimCl ionic liquid at $\mathrm{Pt}$ electrode at $373 \mathrm{~K}$ was also studied by Jagadeeswara Rao et al. [57]. Again, the reduction of $\mathrm{Eu}(\mathrm{III}), \mathrm{Sm}(\mathrm{III})$, and $\mathrm{Ce}(\mathrm{III})$ to the corresponding divalent ions was quasireversible. The apparent standard potentials and the thermodynamic parameters for the reduction reaction were determined and reported in this paper. Matsumiya et al. [58] reported the electrochemical behavior of $\mathrm{Eu}(\mathrm{III})$ and $\mathrm{Sm}(\mathrm{III})$ in ionic liquids, $\mathrm{P}_{2225} \mathrm{NTf}_{2}$ and $\mathrm{N}_{2225} \mathrm{NTf}_{2}$. From the redox potentials, the authors reported that the donor property of phosphonium-based ionic liquids was slightly larger than that of nitrogen-based ionic liquids.

The electrochemical behavior of Eu(III) [24] and U(IV) [59] in $\mathrm{BMPyNTf}_{2}$ and $\mathrm{MPPiNTf}_{2}$, respectively, was studied by Jagadeeswara Rao et al. The europium oxide $\left(\mathrm{Eu}_{2} \mathrm{O}_{3}\right)$ and uranium oxide $\left(\mathrm{UO}_{2}\right)$ were dissolved in RTIL medium and the electrochemical behavior of Eu(III) in BMPyNTf and U(IV) in $\mathrm{MPPiNTf}_{2}$ was studied by various transient electrochemical techniques. The metallic nature of europium and uranium deposit obtained in the study was confirmed by XRD and EDXRF techniques. The study established the feasibility of dissolving the lanthanide and actinide oxides in ionic liquid medium and recovery in metallic form by electrodeposition. Joseph et al. [60] studied the lithiumassisted electrochemical reduction of $\mathrm{U}_{3} \mathrm{O}_{8}$ in $\mathrm{MPPiNTf}_{2}$ to explore the feasibility of using RTILs for direct electrochemical reduction of uranium oxide at near ambient temperature. The electrochemical behavior of $\mathrm{Li}^{+}$in $\mathrm{MPPiNTf}_{2}$ at stainless steel electrode was investigated by cyclic voltammetry and chronoamperometry. Electrodeposition of metallic lithium on $\mathrm{U}_{3} \mathrm{O}_{8}$ particles contained in a stainless steel basket was carried out to examine the feasibility of reducing $\mathrm{U}_{3} \mathrm{O}_{8}$ to metallic form. The results indicated the feasibility of reducing bulk of $\mathrm{U}_{3} \mathrm{O}_{8}$ to $\mathrm{UO}_{2}$ at near ambient temperature. However, reduction of $\mathrm{UO}_{2}$ to metallic form was not observed under the present conditions.

\section{Electrochemical Behavior of Fission Products in Ionic Liquids}

5.1. Cesium and Strontium. Cesium-137 and Strontium-90 are the major radiotoxic fission product isotopes present in high-level liquid waste. Chen and Hussey [61] studied the electrochemistry of the electropositive fission product, $\mathrm{Cs}$, at mercury electrode using $\mathrm{Bu}_{3} \mathrm{MeNNTf}_{2}$ by various voltammetric techniques. The reduction of $\mathrm{Cs}^{+}$at mercury electrode was quasireversible and a diffusion coefficient of $\sim 10^{-8} \mathrm{~cm}^{2} / \mathrm{s}$ at $303 \mathrm{~K}$ was reported. Deposition/stripping was conducted at mercury film electrode with recovery of $97 \%$ of loaded cesium.

Chen and Hussey [62] also reported the selective extraction of $\mathrm{Cs}^{+}$and $\mathrm{Sr}^{2+}$ from aqueous solutions by using the ionophores calix[4] arene-bis(tert-octylbenzo-crown-6) (BOBCalixC6) and dicyclohexano-18-crown-6 (DCH18C6), respectively, present in the hydrophobic, ionic liquid, $\mathrm{Bu}_{3} \mathrm{MeNNTf}_{2}$. The electrochemistry of $\mathrm{Cs}^{+}$coordinated by BOBCalixC6 and $\mathrm{Sr}^{2+}$ coordinated by DCH18C6 was examined at mercury film electrode (MFE) by using cyclic staircase voltammetry, sampled current voltammetry at a rotating electrode, and chronoamperometry. Both BOBCalixC6 $2 \mathrm{Cs}^{+}$and DCH18C6 $\cdot \mathrm{Sr}^{2+}$ exhibited welldefined reduction waves at approximately -2.4 and $-2.9 \mathrm{~V}$ versus the ferrocene/ferrocenium $\left(\mathrm{Fc} / \mathrm{Fc}^{+}\right)$couple, respectively. The coordinated metals were reduced to their respective amalgams, permitting the recycling of the ionophores. 
Chen [63] reported the extraction of $\mathrm{Sr}^{2+}$ and $\mathrm{Cs}^{+}$ from aqueous solutions by using the ionophores dicyclohexano-18-crown-6 (DCH18C6) and calix[4] arene-bis(tertoctylbenzo-crown-6) (BOBCalixC6), respectively, in the hydrophobic, ionic liquid, $\mathrm{Bu}_{3} \mathrm{MeNNTf}_{2}$. The possibility of using the electrodeposition technique to recycle the ionic liquid and the ionophores employed for extraction of $\mathrm{Sr}^{2+}$ and $\mathrm{Cs}^{+}$ions was explored.

5.2. Platinum Group Metals. Spent nuclear fuel is composed of strategic metals such as uranium, and plutonium and potentially useful fission byproducts such as palladium, ruthenium, and rhodium. Significant quantities of platinum groups metals (PGMs) are produced as fission products [64]. Most of the fission PGM isotopes in the spent nuclear fuel are nonradioactive or very weakly radioactive. These fission PGM's are routed to high-level liquid waste (HLLW) during reprocessing of the spent nuclear fuel. Therefore, the HLLW as well as the spent nuclear fuel inself are the valuble resources of man-made noble metals.

Recovery of valuable PGMs from nuclear HLLW was extensively studied [65-70] in the last two decades with particular interest in the separation of palladium. Several authors have reported the electrochemical recovery of PGMs from nitric acid medium [71-75]. Kirshin and Pokhitonov [73] studied the electrolytic recovery of palladium from nitric acid solutions and reported the efficiency of the process in the presence of $\mathrm{HNO}_{3}, \mathrm{NaNO}_{3}$, uranium, and other admixtures. Varentsov and Varentsova [74] reported the electrodeposition of rhodium on carbon fiber electrodes from nitric acid and confirmed that speciation of rhodium strongly affects the deposition behavior. Koizumi and Kawata [75] reported the electrolytic extraction of fission platinoids from nitric acid medium. Recoveries of $90 \%, 23 \%$, and $10 \%$ were reported, respectively, for the deposition of $\mathrm{Pd}, \mathrm{Rh}$, and $\mathrm{Ru}$, and the deposition rates were reported to decrease with increase in nitric acid concentration.

The electrochemical behavior of PGMs, namely, ruthenium (III), rhodium (III), and palladium (II) in HLLW as well as ionic liquid medium was studied by Jayakumar et al. [76, 77]. Palladium (II) present in nitric acid medium underwent an irreversible single-step two-electron transfer to metallic palladium at stainless steel electrode, and it was quantitatively recovered by electrolysis at $-0.5 \mathrm{~V}$ (versus $\mathrm{Pd}$ ). However, several complications aggravated in the presence of interfering metal ions such as silver, nitrate, and iron that are likely to present in HLLW during electrolysis. As a result, the recovery and Faradaic efficiency was dropped below 30\% when electrolysis was carried out with simulated wastes.

Later a novel approach, extraction-electrodeposition (EX-EL) method, was developed by the same group for the quantitative recovery of palladium from simulated HLLW using room-temperature ionic liquid as medium [78]. Initially, Giridhar et al. [79] reported the extraction-electrodeposition (EX-EL) for the separation and recovery of palladium from nitric acid medium using TOMAN ionic liquid. Later, Jayakumar et al. [78] studied the EX-EL process for the recovery of palladium from high-level liquid waste in detail. The process exploited a few remarkable properties of room-temperature ionic liquid, namely, liquid ion exchange behavior and wide electrochemical window to develop a simplified procedure for quantitative recovery of palladium. More than $60 \%$ of palladium was extracted using $0.5 \mathrm{M}$ TOMAN/ $\mathrm{CHCl}_{3}$ in a single contact and complete extraction was achieved in five contacts. The extracted palladium was quantitatively recovered by electrodeposition at stainless steel electrode.

The electrochemical behaviour of $\mathrm{Pd}(\mathrm{II}), \mathrm{Ru}(\mathrm{III})$ and $\mathrm{Rh}$ (III) in ionic liquid is required to understand the feasibility of recovering these noble metals directly from the spent nuclear fuel by nonaqueous processing routes. In this context, the electrochemical behavior of palladium(II) in the basic aluminium chloride + emimCl ionic liquid at glassy carbon, tungsten, and platinum electrodes was reported by Sun and Hussey [80]. A single-step two-electron reduction of $\mathrm{Pd}(\mathrm{II})$ to $\mathrm{Pd}(0)$ was reported. In addition, a nucleation loop was also observed. Hussey et al. [81] reported an electrochemical study of the ruthenium(III) and (IV) hexachlorometallates in a basic room-temperature chloroaluminate molten salt. Ruthenium(IV) showed a couple of reduction waves in the cyclic voltammogram. The first wave corresponds to the reduction of $\mathrm{Ru}(\mathrm{IV})$ to $\mathrm{Ru}(\mathrm{III})$ and the second reduction was attributed to the multielectron reduction of $\mathrm{Ru}(\mathrm{III})$ to other unknown ruthenium complexes. De long et al. $[82,83]$ studied the electrodeposition of palladium from $\mathrm{AlCl}_{3}$-emimCl ionic liquid and adsorption of palladium chloride on solid electrodes. Electrodeposition of palladium in the melt was dependent on the mole fraction of $\mathrm{AlCl}_{3}$ and the reduction potential was shifted to $\sim+2.0 \mathrm{~V}$, when the melt was changed from basic to acidic.

Crisp et al. [84] reported the reduction of dioxotetrachlororuthenate(VI) to hexachlororuthenate(IV) in a basic 1-butylpyridinium chloride-aluminum(III) chloride ionic liquid. The authors have indicated that the redox system was the first irreversible transfer of an oxide ion from an tetrachloroaluminate in an ambient temperature ionic liquid. Electrodeposition of palladium-silver [85] and palladiumindium [86] from a Lewis basic emimCl/emimBF 4 ionic liquid was reported by Sun and coworkers. Since the reduction potentials of $\mathrm{Ag}(\mathrm{I})$ and $\mathrm{Pd}(\mathrm{II})$ were very close to each other and alloy formation was observed [87]. In the case of palladium-indium [86], over potential deposition (OPD) of palladium was reported in the presence of indium; however, underpotential deposition was observed for indium in the presence of palladium.

Bando et al. [88] investigated the electrodeposition of palladium in a hydrophobic BMPyNTf 2 room-temperature ionic liquid. The irreversible reduction of $\mathrm{PdBr}_{4}{ }^{2-}$ and $\mathrm{PdCl}_{4}{ }^{2-}$ to $\mathrm{Pd}(0)$ was observed in this ionic liquid, and the authors have reported that the reduction potential of $\mathrm{PdCl}_{4}{ }^{2-}$ was more negative than that of $\mathrm{PdBr}_{4}{ }^{2-}$, reflecting the difference in the donor property between chloride and bromide. Giridhar et al. studied the feasibility of recovering fission palladium from bmimCl medium [85] and extraction-electrodeposition procedure using Aliquat 336 ionic liquid [79]. However, the electrochemical behavior of $\mathrm{Pd}(\mathrm{II}), \mathrm{Rh}(\mathrm{III})$, and $\mathrm{Ru}(\mathrm{III})$ in bmimCl was studied in detail 
by Jayakumar et al. [89-91]. Electrowinning of palladium was conveniently carried out at $-0.8 \mathrm{~V}$ (versus $\mathrm{Pd}$ ) at stainless steel electrode, whereas the electrodeposition of rhodium was feasible only at $-1.6 \mathrm{~V}$. In contrast to both these metal ions, ruthenium (III) formed a stable solution with bmimCl, and reduction of $\mathrm{Ru}$ (III) in to metallic form was not feasible in bmimCl. However, coexistence of palladium (II) in bmimCl favored underpotential deposition of ruthenium and rhodium. Initial deposition of palladium on working electrode seems to shift the deposition potentials of ruthenium (III) and rhodium (III) and favored underpotential deposition by more than $1 \mathrm{~V}$. The study established the feasibility of using bmimCl ionic liquid as electrolyte for the electrochemical recovery of fission platinoids at $373 \mathrm{~K}$.

Raz et al. [92] studied the electrodeposition of ruthenium on n-type silicon from bmimPF 6 . The reduction of ruthenium occurred at $-2.1 \mathrm{~V}$ (versus $\mathrm{Pt}$ ) and the stripping at $0.2 \mathrm{~V}$ (versus Pt). Metallic Ru film of $\sim 100 \mathrm{~nm}$ thickness was deposited and characterized by scanning electron microscopy (SEM) and X-ray photoelectron spectroscopy (XPS). Mann et al. [93] studied the electrodeposition of ultra thin ruthenium films on $\mathrm{Au}(111)$ substrate from bmimDCA ionic liquid medium. Matsumiya et al. [58] reported the electrochemical behavior of $\left[\mathrm{PdCl}_{4}\right]^{2-}$ and $\left[\mathrm{PdBr}_{4}\right]^{2-}$ in room-temperature ionic liquids, $\mathrm{P}_{2225} \mathrm{NTf}_{2}, \mathrm{P}_{222(12)} \mathrm{NTf}_{2}$, and $\mathrm{N}_{2225} \mathrm{NTf}_{2}$. They mentioned that the diffusion coefficients of palladium complex in phosphonium-based ionic liquids were slightly larger than those in corresponding ammonium counterparts and close to those in $\mathrm{BMPyNTf}_{2}$.

5.3. Thermal and Radiation Stability. Ionic liquids with good radiation and thermal stability are indeed necessary for nuclear fuel cycle applications. Moura Ramos et al. [94] investigated the glass transition of imidazolium-based RTILs such as $\mathrm{C}_{5} \mathrm{O}_{2} \mathrm{ImCl}$ and $\mathrm{C}_{5} \mathrm{O}_{2} \mathrm{ImPF}_{6}{ }^{-}$and reported the heat capacity jump during glass transition. Zhang et al. $[95,96]$ determined the molar heat capacities of $\mathrm{BuPyBF}_{4}$ and bmimBF 4 using adiabatic calorimeter and reported the enthalpy and entropy change during glass transition of RTIL. Reddy and coworkers [97] reported some thermodynamic properties of bmimCl determined by using techniques such as TG, DTA, and DSC. Jagadeeswara Rao et al. [98] reported the thermal stabilities and heat capacities of various ionic liquids such as MPPiNTf 2 , BMPyNTf 2 , and HbetNTf 2 . The ionic liquids, MPPiNTf 2 , and BMPyNTf $f_{2}$, were reported to be thermally stable up to $650 \mathrm{~K}$, whereas $\mathrm{HbetNTf}_{2}$ was stable only up to $560 \mathrm{~K}$.

Allen et al. [99] investigated the radiation stability of 1, 3-dialkylimidazolium nitrate/chloride ionic liquids and reported that their stabilities are comparable with that of benzene and more stable than the mixtures of tributylphosphate and odourless kerosene under similar irradiation conditions. These ionic liquids were reported as radiation resistant up to $400 \mathrm{kGy}$, and it was attributed to the combination of properties of a salt and aromaticity. Berthon et al. [100] studied the gamma radiolysis of hydrophobic ionic liquids bmimPF 6 and bmimNTf 2 . It was reported that the properties such as density, surface tension, and refractive index were unchanged upon irradiation; however, significant increase in viscosities and lowering of conductivity was observed in case of irradiated RTILs. Moreover, the overall concentrations of radiolysis products did not exceed $1 \mathrm{~mol} \%$ when irradiated up to $1200 \mathrm{kGy}$. Jagadeeswara Rao et al. [22] also reported a similar observation for the ionic liquids such as, bmimCl, hmimCl, HbetNTf 2, BMPyNTf $_{2}$, MPPiNTf $_{2}$, and aliquat 336 ionic liquids upon gamma irradiation.

Lall-Ramnarine et al. [101] investigated pulse radiolysis of bis(oxalato)borate anion-based ionic liquids. Efficient scavenging of radiolytically generated electrons was observed in these ionic liquids. It was suggested that these borated ionic liquids may find useful applications during handling of concentrated fissile elements. Tarábek et al. [102] studied the electron beam radiolysis of several $\mathrm{NTf}_{2}{ }^{-}$-based ionic liquids. The study revealed that the formation of hydrogen gas due to radiolysis of ionic liquids was relatively low compared to aliphatic and aromatic organic compounds. Ionic liquids with imidazolium and pyridinium cations were reported to give smallest hydrogen yields. Yuan et al. [103] studied the gamma radiolysis of bmimNTf $\mathrm{f}_{2}$. It was reported that the absorbance of ionic liquids at $290 \mathrm{~nm}$ increased with increase of absorbed dose, and it was attributed to the radiolysis of bmim ${ }^{+}$cation. Qi et al. [104] studied the gamma radiation effect on bmimBF 4 . They reported that the irradiation-induced darkness and increased the UV absorption, but it did not affect the glass transition point of bmimBF . They concluded that the radiation stability of bmimBF$_{4}$ was higher than bmimPF 6 .

\section{Conclusions}

RTILs initially introduced as a substitute to the molecular diluent, $\mathrm{n}$-dodecane, in aqueous reprocessing applications, are now receiving an upsurge in the studies related to nonaqueous reprocessing. The discovery of the moisture stable ionic liquids in late 1990s having wide electrochemical window $(\sim 6 \mathrm{~V})$ and excellent cathodic stability indeed boosted the ionic liquid research for such applications. The electrochemical behavior of actinides and fission products in moisture stable ionic liquids reported so far are encouraging, and, going by the research work published recently, it appears that ionic liquids have good potential for nonaqueous processing applications. While these new results and novel technologies exhibit a great potential, the physical and chemical properties of the ionic liquid needs to be tuned to suit the ionic liquid for robust applications. It is, therefore, recommended to study the fundamental properties of ionic liquids that govern electrochemical stability, solubility of actinides and fission products, viscosity, and so forth to design RTILs having all the required properties for the desirable applications.

\section{References}

[1] D. Olander, "Nuclear fuels_-Present and future," Journal of Nuclear Materials, vol. 389, no. 1, pp. 1-22, 2009.

[2] J. 1. Swanson, "PUREX process flowsheets," in Science and Technology of Tributyl phosphate, W. W. Schulz, L. L. Burger, 
J. D. Navratil, and K. P. Bender, Eds., p. 55, CRC Press, Boca Raton, Fla, USA, 1984.

[3] A. V. Bychkov and O. V. Skiba, "Review of non-aqueous nuclear fuel reprocessing and separation methods," in Chemical Separation Technologies and Related Methods of Nuclear Waste Management, G. R. Choppin and M. Kh. Khankhasayev, Eds., pp. 71-98, Kluwer Academic, Dodrecht, The Netherlands, 1999.

[4] T. Nishimura, T. Koyama, M. Iizuka, and H. Tanaka, "Development of an environmentally benign reprocessing technology-Pyrometallurgical reprocessing technology," Progress in Nuclear Energy, vol. 32, no. 3-4, pp. 381-387, 1998.

[5] V. A. Cocalia, K. E. Gutowski, and R. D. Rogers, "The coordination chemistry of actinides in ionic liquids: a review of experiment and simulation," Coordination Chemistry Reviews, vol. 250, no. 7-8, pp. 755-764, 2006.

[6] K. R. Seddon, "Ionic liquids: a taste of the future," Nat Mater, vol. 2, no. 6, pp. 363-365, 2003.

[7] M. Freemantle, An Introduction to Ionic Liquids, RSC Publishing, Cambridge, UK, 2010.

[8] N. V. Plechkova and K. R. Seddon, "Applications of ionic liquids in the chemical industry," Chemical Society Reviews, vol. 37, no. 1, pp. 123-150, 2008.

[9] T. Tsuda and C. L. Hussey, "Electrochemical applications of room-temperature ionic liquids," Electrochemical Society Interface, vol. 16, no. 1, pp. 42-49, 2007.

[10] P. R. Vasudeva Rao, K. A. Venkatesan, and T. G. Srinivasan, "Studies on applications of room temperature ionic liquids," Progress in Nuclear Energy, vol. 50, no. 2-6, pp. 449-455, 2008.

[11] D. Wei and A. Ivaska, "Applications of ionic liquids in electrochemical sensors," Analytica Chimica Acta, vol. 607, no. 2, pp. 126-135, 2008.

[12] P. J. Dyson and T. J. Geldbach, "Applications of ionic liquids in synthesis and catalysis," Electrochemical Society Interface, vol. 16, no. 1, pp. 50-53, 2007.

[13] K. Binnemans, "Lanthanides and actinides in ionic liquids," Chemical Reviews, vol. 107, no. 6, pp. 2592-2614, 2007.

[14] A. J. Fry, "Solvent and supporting electrolytes," in Laboratory Techniques in Electroanalytical Chemistry, P. T. Kissinger and W. R. Heineman, Eds., pp. 467-485, Marcel Dekker, New York, NY, USA, 1996.

[15] F. Endres and S. Zein El Abedin, "Air and water stable ionic liquids in physical chemistry," Physical Chemistry Chemical Physics, vol. 8, no. 18, pp. 2101-2116, 2006.

[16] W. Simka, D. Puszczyk, and G. Nawrat, "Electrodeposition of metals from non-aqueous solutions," Electrochimica Acta, vol. 54, no. 23, pp. 5307-5319, 2009.

[17] F. Endres, A. P. Abbott, and D. R. Mac Farlane, Electrodeposition from Ionic Liquids, Wiley- $\mathrm{VCH}$, Weinheim, Germany, 2008.

[18] P. Giridhar, K. A. Venkatesan, T. G. Srinivasan, and P. R. V. Rao, "Electrochemical behavior of uranium(VI) in 1-butyl3-methylimidazolium chloride and thermal characterization of uranium oxide deposit," Electrochimica Acta, vol. 52, no. 9, pp. 3006-3012, 2007.

[19] S. S. Moganty, R. E. Baltus, and D. Roy, "Electrochemical windows and impedance characteristics of $\left[\mathrm{Bmim}^{+}\right]\left[\mathrm{BF}_{4}\right]$ and $\left[\mathrm{Bdmim}^{+}\right]\left[\mathrm{BF}_{4}\right]$ ionic liquids at the surfaces of $\mathrm{Au}, \mathrm{Pt}$, Ta and glassy carbon electrodes," Chemical Physics Letters, vol. 483, no. 1-3, pp. 90-94, 2009.

[20] P. A. Z. Suarez, V. M. Selbach, J. E. L. Dullius et al., "Enlarged electrochemical window in dialkyl-imidazolium cation based room-temperature air and water-stable molten salts," Electrochimica Acta, vol. 42, no. 16, pp. 2533-2535, 1997.

[21] M. B. Herath, T. Hickman, S. E. Creager, and D. D. Desmarteau, "A new fluorinated anion for room-temperature ionic liquids," Journal of Fluorine Chemistry, vol. 132, no. 1, pp. 52-56, 2011.

[22] C. Jagadeeswara Rao, K. A. Venkatesan, B. V. R. Tata, K. Nagarajan, T. G. Srinivasan, and P. R. Vasudeva Rao, "Radiation stability of some room temperature ionic liquids," Radiation Physics and Chemistry, vol. 80, no. 5, pp. 643-649, 2011.

[23] C. J. Rao, K. A. Venkatesan, K. Nagarajan, and T. G. Srinivasan, "Dissolution of uranium oxides and electrochemical behavior of U(VI) in task specific ionic liquid," Radiochimica Acta, vol. 96, no. 7, pp. 403-409, 2008.

[24] C. Jagadeeswara Rao, K. A. Venkatesan, K. Nagarajan, T. G. Srinivasan, and P. R. Vasudeva Rao, "Electrochemical behavior of europium (III) in N-butyl-N-methylpyrrolidinium bis(trifluoromethylsulfonyl)imide," Electrochimica Acta, vol. 54, no. 20, pp. 4718-4725, 2009.

[25] M. Shamsipur, A. A. M. Beigi, M. Teymouri, S. M. Pourmortazavi, and M. Irandoust, "Physical and electrochemical properties of ionic liquids 1-ethyl-3-methylimidazolium tetrafluoroborate, 1-butyl-3-methylimidazolium trifluoromethanesulfonate and 1-butyl-1-methylpyrrolidinium bis(trifluoromethylsulfonyl)imide," Journal of Molecular Liquids, vol. 157, no. 1, pp. 43-50, 2010.

[26] D. R. MacFarlane, P. Meakin, J. Sun, N. Amini, and M. Forsyth, "Pyrrolidinium imides: a new family of molten salts and conductive plastic crystal phases," Journal of Physical Chemistry B, vol. 103, no. 20, pp. 4164-4170, 1999.

[27] H. Sakaebe and H. Matsumoto, "N-methyl-N-propylpiperidinium bis(trifluoromethanesulfonyl)imide (PP13TFSI_-Novel electrolyte base for Li battery," Electrochemistry Communications, vol. 5, no. 7, pp. 594-598, 2003.

[28] K. Tsunashima, S. Kodama, M. Sugiya, and Y. Kunugi, "Physical and electrochemical properties of room-temperature dicyanamide ionic liquids based on quaternary phosphonium cations," Electrochimica Acta, vol. 56, no. 2, pp. 762766, 2010.

[29] K. Tsunashima and M. Sugiya, "Physical and electrochemical properties of low-viscosity phosphonium ionic liquids as potential electrolytes," Electrochemistry Communications, vol. 9, no. 9, pp. 2353-2358, 2007.

[30] T. Nishida, Y. Tashiro, and M. Yamamoto, "Physical and electrochemical properties of 1-alkyl-3-methylimidazolium tetrafluoroborate for electrolyte," Journal of Fluorine Chemistry, vol. 120, no. 2, pp. 135-141, 2003.

[31] R. De Waele, L. Heerman, and W. D'Olieslager, "Potentiometric and spectroscopic study of uranium(IV)uranium(III) in acidic $\mathrm{AlCl}_{3}-\mathrm{N}$-(n-BUTYL) pyridinium chloride melts," Journal of The Less-Common Metals, vol. 122, no. C, pp. 319-327, 1986.

[32] R. de Waele, L. Heerman, and W. D'olieslager, "Electrochemistry of uranium(IV) in acidic $\mathrm{AlCl}_{3}+\mathrm{N}-(\mathrm{n}-$ butyle)pyridinium chloride room-temperature molten salts," Journal of Electroanalytical Chemistry, vol. 142, no. 1-2, pp. 137-146, 1982.

[33] L. Heerman, R. De Waele, and W. D'Olieslager, "Electrochemistry and spectroscopy of uranium in basic $\mathrm{AlCl}_{3}+$ $\mathrm{N}$-(n-butyl)pyridinium chloride room temperature molten salts," Journal of Electroanalytical Chemistry, vol. 193, no. 12, pp. 289-294, 1985. 
[34] P. B. Hitchcock, T. J. Mohammed, K. R. Seddon, J. A. Zora, C. L. Hussey, and E. Haynes Ward, "1-methyl-3ethylimidazolium hexachlorouranate(IV) and 1-methyl-3ethylimidazolium tetrachlorodioxo-uranate(VI): synthesis, structure, and electrochemistry in a room temperature ionic liquid," Inorganica Chimica Acta, vol. 113, no. 2, pp. L25-L26, 1986.

[35] C. J. Anderson, M. R. Deakin, G. R. Choppin, W. D'Olieslager, L. Heerman, and D. J. Pruett, "Spectroscopy and electrochemistry of $\mathrm{U}(\mathrm{IV}) / \mathrm{U}(\mathrm{III})$ in basic aluminum chloride-1-ethyl-3-methylimidazolium chloride," Inorganic Chemistry, vol. 30, no. 21, pp. 4013-4016, 1991.

[36] N. Asanuma, M. Harada, Y. Yasuike, M. Nogami, K. Suzuki, and Y. Ikeda, "Electrochemical properties of uranyl ion in ionic liquids as media for pyrochemical reprocessing," Journal of Nuclear Science and Technology, vol. 44, no. 3, pp. 368-372, 2007.

[37] Y. Ikeda, K. Hiroe, N. Asanuma, and A. Shirai, "Electrochemical studies on uranyl (VI) chloride complexes in ionic liquid, 1-Butyl-3-methylimidazolium chloride," Journal of Nuclear Science and Technology, vol. 46, no. 2, pp. 158-162, 2009.

[38] Y. Ohashi, N. Asanuma, M. Harada, Y. Wada, T. Matsubara, and Y. Ikeda, "Application of ionic liquid as a medium for treating waste contaminated with $\mathrm{UF}_{4}$," Journal of Nuclear Science and Technology, vol. 46, no. 8, pp. 771-775, 2009.

[39] J. P. Schoebrechts and B. Gilbert, "Electrochemical and spectroscopic studies of neptunium in the aluminum chloride-1n-butylpyridinium chloride melt at $40^{\circ} \mathrm{C}$," Inorganic Chemistry, vol. 24, no. 13, pp. 2105-2110, 1985.

[40] C. J. Andersen, G. R. Choppin, D. J. Pruett, D. Costa, and W. Smith, "Electrochemistry and spectroscopy of $\mathrm{UO}_{2}^{2+}$ in acidic $\mathrm{AlCl}_{3}$-EMIC," Radiochimica Acta, vol. 84, no. 1, pp. 31-36, 1999.

[41] M. Deetlefs, C. L. Hussey, T. J. Mohammed, K. R. Seddon, J. A. Van Den Berg, and J. A. Zora, "Uranium halide complexes in ionic liquids: an electrochemical and structural study," Dalton Transactions, no. 19, pp. 2334-2341, 2006.

[42] F. M. Lin and C. L. Hussey, "Electrochemical and spectroscopic study of cerium in the basic aluminum chloride-1methyl-3-ethylimidazolium chloride molten salt," Journal of the Electrochemical Society, vol. 140, no. 11, pp. 3093-3096, 1993.

[43] J. P. Schoebrechts, B. P. Gilbert, and G. Duyckaerts, "Electrochemical and spectroscopic studies of the lanthanides in the $\mathrm{AlCl}_{3}+1$-n-butylpyridinium chloride melt at $40^{\circ} \mathrm{C}$. Part I. The Yb(III-II), Sm(III-II) systems," Journal of Electroanalytical Chemistry, vol. 145, no. 1, pp. 127-138, 1983.

[44] J. P. Schoebrechts, B. P. Gilbert, and G. Duyckaerts, "Electrochemical and spectroscopic studies of the lanthanides in the $\mathrm{AlCl}_{3},+1$-n-butylpyridinium chloride melt at $40^{\circ} \mathrm{C}$. Part II. The Tm(III-II), Eu(III-II) systems, application of nugent's linearization method," Journal of Electroanalytical Chemistry, vol. 145, no. 1, pp. 139-146, 1983.

[45] M. Galiński, A. Lewandowski, and I. Stepniak, "Ionic liquids as electrolytes," Electrochimica Acta, vol. 51, no. 26, pp. 55675580, 2006.

[46] E. I. Rogers, B. Sljukic, C. Hardacre, and R. G. Compton, "Electrochemistry in room-temperature ionic liquids: potential windows at mercury electrodes," Journal of Chemical and Engineering Data, vol. 54, no. 7, pp. 2049-2053, 2009.

[47] S. Zhang, X. Lu, Q. Zhou, X. Li, and X. Zhang, Ionic Liquids: Physicochemical Properties, Elsevier, Oxford, UK, 2009.
[48] S. I. Nikitenko, C. Cannes, C. Le Naour, P. Moisy, and D. Trubert, "Spectroscopic and Electrochemical Studies of $\mathrm{U}(\mathrm{IV})$-Hexachloro Complexes in Hydrophobic Room-Temperature Ionic Liquids [BuMeIm] $\left[\mathrm{NTf}_{2}\right]$ and $\left[\mathrm{MeBu}_{3} \mathrm{~N}\right]\left[\mathrm{NTf}_{2}\right]$," Inorganic Chemistry, vol. 44, no. 25, pp. 9497-9505, 2005.

[49] S. I. Nikitenko, C. Hennig, M. S. Grigoriev et al., "Structural and spectroscopic studies of the complex $[\mathrm{BuMeIm}]_{2}\left[\mathrm{UCl}_{6}\right]$ in the solid state and in hydrophobic room temperature ionic liquid [BuMeIm] $\left[\mathrm{Tf}_{2} \mathrm{~N}\right]$," Polyhedron, vol. 26, no. 13, pp. 3136-3142, 2007.

[50] S. I. Nikitenko and P. Moisy, "Formation of higher chloride complexes of $\mathrm{Np}(\mathrm{IV})$ and $\mathrm{Pu}(\mathrm{IV})$ in water-stable roomtemperature ionic liquid [BuMeIm] $\left[\mathrm{Tf}_{2} \mathrm{~N}\right]$," Inorganic Chemistry, vol. 45, no. 3, pp. 1235-1242, 2006.

[51] A. I. Bhatt, I. May, V. A. Volkovich et al., "Group 15 quaternary alkyl bistriflimides: Ionic liquids with potential application in electropositive metal deposition and as supporting electrolytes," Journal of the Chemical Society. Dalton Transactions, no. 24, pp. 4532-4534, 2002.

[52] A. I. Bhatt, I. May, V. A. Volkovich et al., "Structural characterization of a lanthanum bistriflimide complex, $\mathrm{La}\left(\mathrm{N}\left(\mathrm{SO}_{2} \mathrm{CF}_{3}\right)_{2}\right)_{3}\left(\mathrm{H}_{2} \mathrm{O}\right)_{3}$, and an investigation of $\mathrm{La}, \mathrm{Sm}$, and $\mathrm{Eu}$ electrochemistry in a room-temperature ionic liquid, $\left[\mathrm{Me}_{3} \mathrm{NnBu}\right]\left[\mathrm{N}\left(\mathrm{SO}_{2} \mathrm{CF}_{3}\right)_{2}\right]$," Inorganic Chemistry, vol. 44, no. 14, pp. 4934-4940, 2005.

[53] A. I. Bhatt, N. W. Duffy, D. Collison, I. May, and R. G. Lewin, "Cyclic voltammetry of $\mathrm{Th}(\mathrm{IV})$ in the room-temperature ionic liquid $\left[\mathrm{Me}_{3} \mathrm{NnBu}\right]\left[\mathrm{N}\left(\mathrm{SO}_{2} \mathrm{CF}_{3}\right)_{2}\right]$," Inorganic Chemistry, vol. 45, no. 4, pp. 1677-1682, 2006.

[54] S. Legeai, S. Diliberto, N. Stein et al., "Room-temperature ionic liquid for lanthanum electrodeposition," Electrochemistry Communications, vol. 10, no. 11, pp. 1661-1664, 2008.

[55] R. Nagaishi, M. Arisaka, T. Kimura, and Y. Kitatsuji, "Spectroscopic and electrochemical properties of europium(III) ion in hydrophobic ionic liquids under controlled condition of water content," Journal of Alloys and Compounds, vol. 431, no. 1-2, pp. 221-225, 2007.

[56] M. Yamagata, Y. Katayama, and T. Miura, "Electrochemical behavior of samarium, europium, and ytterbium in hydrophobic room-temperature molten salt systems," Journal of the Electrochemical Society, vol. 153, no. 1, pp. E5-E9, 2006.

[57] C. Jagadeeswara Rao, K. A. Venkatesan, K. Nagarajan, T. G. Srinivasan, and P. R. Vasudeva Rao, "Electrochemical and thermodynamic properties of europium(III), samarium(III) and cerium(III) in 1-butyl-3-methylimidazolium chloride ionic liquid," Journal of Nuclear Materials, vol. 399, no. 1, pp. 81-86, 2010.

[58] M. Matsumiya, S. Suda, K. Tsunashima, M. Sugiya, S. Y. Kishioka, and H. Matsuura, "Electrochemical behaviors of multivalent complexes in room temperature ionic liquids based on quaternary phosphonium cations," Journal of Electroanalytical Chemistry, vol. 622, no. 2, pp. 129-135, 2008.

[59] C. Jagadeeswara Rao, K. A. Venkatesan, K. Nagarajan, T. G. Srinivasan, and P. R. Vasudeva Rao, "Electrodeposition of metallic uranium at near ambient conditions from room temperature ionic liquid," Journal of Nuclear Materials, vol. 408, no. 1, pp. 25-29, 2011.

[60] B. Joseph, K. A. Venkatesan, K. Nagarajan, T. G. Srinivasan, and P. R. Vasudeva Rao, "Lithium assisted electrochemical reduction of uranium oxide in room temperature ionic liquid," Journal of Radioanalytical and Nuclear Chemistry, vol. 287, pp. 167-171, 2011. 
[61] P. Y. Chen and C. L. Hussey, "Electrodeposition of cesium at mercury electrodes in the tri-1-butylmethylammonium bis((trifluoromethyl)sulfonyl)imide room-temperature ionic liquid," Electrochimica Acta, vol. 49, no. 28, pp. 5125-5138, 2004.

[62] P. Y. Chen and C. L. Hussey, "Electrochemistry of ionophorecoordinated $\mathrm{Cs}$ and $\mathrm{Sr}$ ions in the tri-1-butylmethylammonium bis((trifluoromethyl)sulfonyl)imide ionic liquid," Electrochimica Acta, vol. 50, no. 12, pp. 2533-2540, 2005.

[63] P. Y. Chen, "The assessment of removing strontium and cesium cations from aqueous solutions based on the combined methods of ionic liquid extraction and electrodeposition," Electrochimica Acta, vol. 52, no. 17, pp. 5484-5492, 2007.

[64] H. J. Ache, L. H. Baetsle, R. P. Busth, A. F. Nechaev, V. P. Popik, and Y. Ying, "Feasibility of separation and utilization of ruthenium, rhodium and palladium from high level waste," Tech. Rep. 308, International Atomic Energy Agency, Vienna, Austria, 1989.

[65] R. J. Newman and F. J. Smith, "Platinum metals from nuclear fission-an evaluation of their possible use by industry," Platinum Metals Review, vol. 14, pp. 88-92, 1970.

[66] G. A. Jenson, A. M. Platt, G. B. Mellinger, and W. J. Bjorklund, "Recover of noble metals from fission products," Journal of Nuclear Science and Technology, vol. 65, pp. 305324, 1984.

[67] G. A. Jenson, C. A. Rohmann, and L. D. Perrigo, Recovery and Use of Fission Product Noble Metals, PNL-SA-8358, Pacific Northwest Laboratory, Richland, Wash, USA, 1980.

[68] Z. Kolarik and E. V. Renard, "Recovery of value fission platinoids from spent nuclear fuel," Platinum Metals Review, vol. 47, no. 2, pp. 74-87, 2003.

[69] Z. Kolarik and E. V. Renard, "Recovery of value fission platinoids from spent nuclear fuel-Part II: Separation processes," Platinum Metals Review, vol. 47, no. 3, pp. 123-131, 2003.

[70] Y. A. Pokhitonov and V. N. Romanovskii, "Palladium in irradiated fuel. Are there any prospects for recovery and application?" Radiochemistry, vol. 47, no. 1, pp. 1-13, 2005.

[71] Y. Kobayashi, H. Yamatera, and H. Okuno, "The electrodeposition of ruthenium from a ruthenium (III) and ruthenium (IV) solution and a fission products solution," Bulletin of the Chemical Society of Japan, vol. 38, pp. 1911-1915, 1965.

[72] M. Ozawa, T. Suzuki, S. I. Koyama, H. Akatsuka, H. Mimura, and Y. Fujii, "A new back-end cycle strategy for enhancing separation, transmutation and utilization of materials (Adv.ORIENT cycle)," Progress in Nuclear Energy, vol. 50, no. 2-6, pp. 476-482, 2008.

[73] M. Y. Kirshin and Y. A. Pokhitonov, "Recovery of Pd from spent fuel: 1. Electrochemical recovery of palladium from nitric acid solutions," Radiochemistry, vol. 47, no. 4, pp. 365369, 2005.

[74] V. K. Varentsov and V. I. Varentsova, "Electrodeposition of rhodium on cathodes of carbon-fiber material from $\mathrm{Rh}(\mathrm{III})$ complexes in nitric acid solutions," Russian Journal of Electrochemistry, vol. 39, no. 6, pp. 703-705, 2003.

[75] K. Koizumi and T. Kawata, "Electrolytic extraction of platinum group metals from dissolver solution of purex process," Journal of Nuclear Science and Technology, vol. 30, no. 11, pp. 1195-1197, 1993.

[76] M. Jayakumar, K. A. Venkatesan, T. G. Srinivasan, and P. R. V. Rao, "Studies on the feasibility of electrochemical recovery of palladium from high-level liquid waste," Electrochimica Acta, vol. 54, no. 3, pp. 1083-1088, 2009.
[77] M. Jayakumar, K. A. Venkatesan, T. G. Srinivasan, and P. R. Vasudeva Rao, "Feasibility studies on the electrochemical recovery of fission platinoids from high-level liquid waste," Journal of Radioanalytical and Nuclear Chemistry, vol. 284, pp. 79-85, 2010.

[78] M. Jayakumar, K. A. Venkatesan, T. G. Srinivasan, and P. R. Vasudeva Rao, "Extraction-electrodeposition (EX-EL) process for the recovery of palladium from high-level liquid waste," Journal of Applied Electrochemistry, vol. 39, no. 10, pp. 1955-1962, 2009.

[79] P. Giridhar, K. A. Venkatesan, T. G. Srinivasan, and P. R. V. Rao, "Extraction of fission palladium by Aliquat 336 and electrochemical studies on direct recovery from ionic liquid phase," Hydrometallurgy, vol. 81, no. 1, pp. 30-39, 2006.

[80] I.-W. Sun and C. L. Hussey, "Electrochemical reduction of palladium(II) in the basic aluminum chloride +1 methyl-3-ethylimidazolium chloride molten salt," Journal of Electroanalytical Chemistry, vol. 274, no. 1-2, pp. 325-331, 1989.

[81] C. L. Hussey, P. A. Barnard, I. W. Sun et al., "Electrochemical study of the ruthenium(III) and -(IV) hexachlorometallates in a basic room temperature chloroaluminate molten salt," Journal of the Electrochemical Society, vol. 138, no. 9, pp. 2590-2594, 1991.

[82] H. C. De Long, J. S. Wilkes, and R. T. Carlin, "Electrodeposition of palladium and adsorption of palladium chloride onto solid electrodes from room temperature molten salts," Journal of the Electrochemical Society, vol. 141, no. 4, pp. 1000-1005, 1994.

[83] H. C. De Long and R. T. Carlin, "Palladium chloride to palladium metal two-dimensional nucleation and growth phenomena," Journal of the Electrochemical Society, vol. 142, no. 8, pp. 2747-2753, 1995.

[84] R. I. Crisp, C. L. Hussey, and K. R. Seddon, "The reduction of dioxotetrachlororuthenate(VI) to hexachlororuthenate(IV) in a basic 1-butylpyridinium chloridealuminium(III) chloride ionic liquid," Polyhedron, vol. 14, no. 19, pp. 2819-2825, 1995.

[85] P. Giridhar, K. A. Venkatesan, B. P. Reddy, T. G. Srinivasan, and P. R. Vasudeva Rao, "Recovery of fission palladium by electrodeposition using room temperature ionic liquids," Radiochimica Acta, vol. 94, no. 3, pp. 131-136, 2006.

[86] S. I. Hsiu, C. C. Tai, and I. W. Sun, "Electrodeposition of palladium-indium from 1-ethyl-3-methylimidazolium chloride tetrafluoroborate ionic liquid," Electrochimica Acta, vol. 51, no. 13, pp. 2607-2613, 2006.

[87] C. C. Tai, F. Y. Su, and I. W. Sun, "Electrodeposition of palladium-silver in a Lewis basic 1-ethyl-3- methylimidazolium chloride-tetrafluoroborate ionic liquid," Electrochimica Acta, vol. 50, no. 28, pp. 5504-5509, 2005.

[88] Y. Bando, Y. Katayama, and T. Miura, "Electrodeposition of palladium in a hydrophobic 1-n-butyl-1-methylpyrrolidinium bis(trifluoromethylsulfonyl)imide room-temperature ionic liquid," Electrochimica Acta, vol.53, no. 1, pp. 87-91, 2007.

[89] M. Jayakumar, K. A. Venkatesan, and T. G. Srinivasan, "Electrochemical behavior of rhodium(III) in 1-butyl-3methylimidazolium chloride ionic liquid," Electrochimica Acta, vol. 53, no. 6, pp. 2794-2801, 2008.

[90] M. Jayakumar, K. A. Venkatesan, and T. G. Srinivasan, "Electrochemical behavior of fission palladium in 1-butyl3-methylimidazolium chloride," Electrochimica Acta, vol. 52, no. 24 , pp. 7121-7127, 2007. 
[91] M. Jayakumar, K. A. Venkatesan, T. G. Srinivasan, and P. R. Vasudeva Rao, "Electrochemical behavior of ruthenium (III), rhodium (III) and palladium (II) in 1-butyl-3methylimidazolium chloride ionic liquid," Electrochimica Acta, vol. 54, no. 26, pp. 6747-6755, 2009.

[92] O. Raz, G. Cohn, W. Freyland, O. Mann, and Y. EinEli, "Ruthenium electrodeposition on silicon from a roomtemperature ionic liquid," Electrochimica Acta, vol. 54, no. 25, pp. 6042-6045, 2009.

[93] O. Mann, W. Freyland, O. Raz, and Y. Ein-Eli, "Electrochemical deposition of ultrathin ruthenium films on $\mathrm{Au}\left(\begin{array}{lll}1 & 1 & 1\end{array}\right)$ from an ionic liquid," Chemical Physics Letters, vol. 460, no. 1-3, pp. 178-181, 2008.

[94] J. J. Moura Ramos, C. A. M. Afonso, and L. C. Branco, "Glass transition relaxation and fragility in two room temperature ionic liquids," Journal of Thermal Analysis and Calorimetry, vol. 71, no. 2, pp. 659-666, 2003.

[95] Z. H. Zhang, Z. C. Tan, Y. S. Li, and L. X. Sun, "Thermodynamic investigation of room temperature ionic liquid : HHHHeat capacity and thermodynamic functions of $\mathrm{BMIBF}_{4}$," Journal of Thermal Analysis and Calorimetry, vol. 85, no. 3, pp. 551-557, 2006.

[96] Z. H. Zhang, L. X. Sun, Z. C. Tan et al., “Thermodynamic investigation of room temperature ionic liquid : HHHeat capacity and thermodynamic functions of $\mathrm{BPBF}_{4}$, " Journal of Thermal Analysis and Calorimetry, vol. 89, no. 1, pp. 289-294, 2007.

[97] M. Zhang, V. Kamavaram, and R. G. Ready, "Thermodynamic properties of 1-butyl-3-methylimidazolium chloride (C 4mim[Cl]) ionic liquid," Journal of Phase Equilibria and Diffusion, vol. 26, no. 2, pp. 124-130, 2005.

[98] C. Jagadeeswara Rao, R. Venkata Krishnan, K. A. Venkatesan, K. Nagarajan, and T. G. Srinivasan, "Thermochemical properties of some bis(trifluoromethyl-sulfonyl)imide based room temperature ionic liquids," Journal of Thermal Analysis and Calorimetry, vol. 97, no. 3, pp. 937-943, 2009.

[99] D. Allen, G. Baston, A. E. Bradley et al., "An investigation of the radiochemical stability of ionic liquids," Green Chemistry, vol. 4, no. 2, pp. 152-158, 2002.

[100] L. Berthon, S. I. Nikitenko, I. Bisel et al., "Influence of gamma irradiation on hydrophobic room-temperature ionic liquids $\left[\right.$ BuMeIm] $\mathrm{PF}_{6}$ and [BuMeIm] $\left(\mathrm{CF}_{3} \mathrm{SO}_{2}\right)_{2} \mathrm{~N}$," Dalton Transactions, no. 21, pp. 2526-2534, 2006.

[101] S. I. Lall-Ramnarine, A. Castano, G. Subramaniam, M. F. Thomas, and J. F. Wishart, "Synthesis, characterization and radiolytic properties of bis(oxalato)borate containing ionic liquids," Radiation Physics and Chemistry, vol. 78, no. 12, pp. 1120-1125, 2009.

[102] P. Tarábek, S. Liu, K. Haygarth, and D. M. Bartels, "Hydrogen gas yields in irradiated room-temperature ionic liquids," Radiation Physics and Chemistry, vol. 78, no. 3, pp. 168-172, 2009.

[103] L. Yuan, J. Peng, L. Xu, M. Zhai, J. Li, and G. Wei, "Radiationinduced darkening of ionic liquid [C4mim][NTf2] and its decoloration," Radiation Physics and Chemistry, vol. 78, no. 12, pp. 1133-1136, 2009.

[104] M. Qi, G. Wu, Q. Li, and Y. Luo, " $\gamma$-Radiation effect on ionic liquid [bmim][BF4]," Radiation Physics and Chemistry, vol. 77, no. 7, pp. 877-883, 2008. 


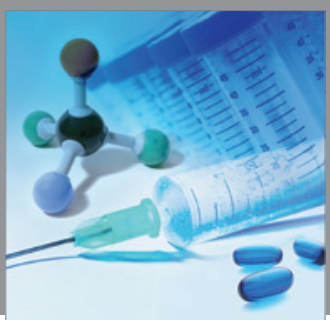

International Journal of

Medicinal Chemistry

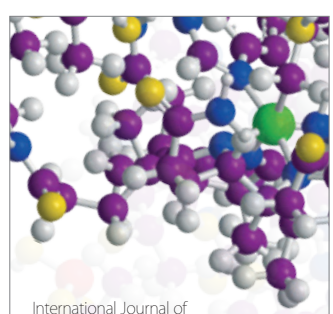

Carbohydrate Chemistry

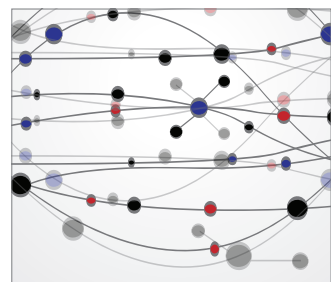

The Scientific World Journal
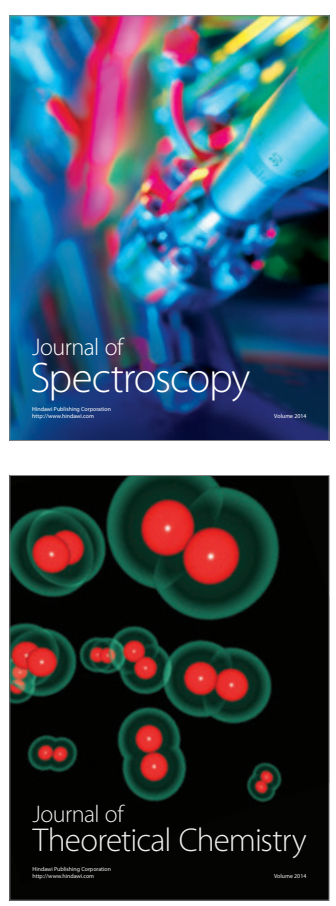
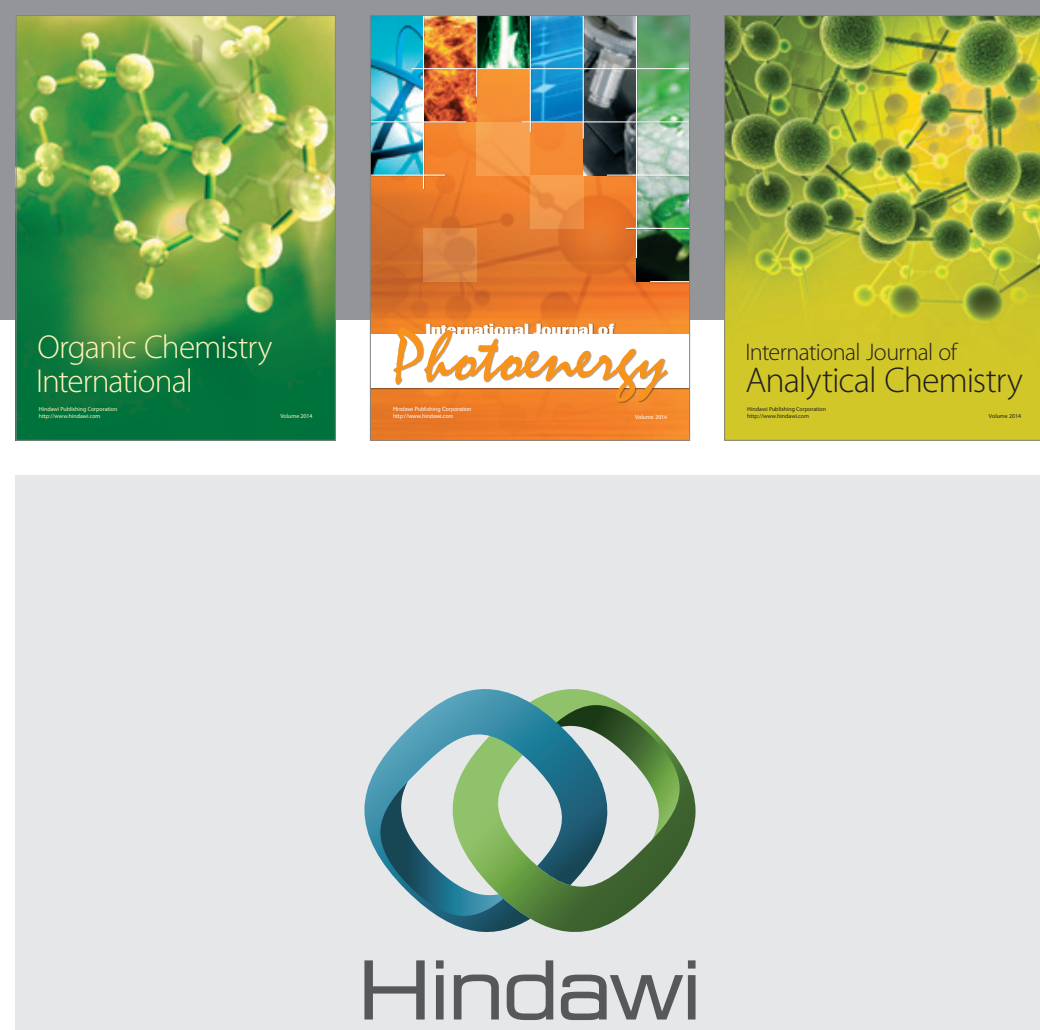

Submit your manuscripts at

http://www.hindawi.com
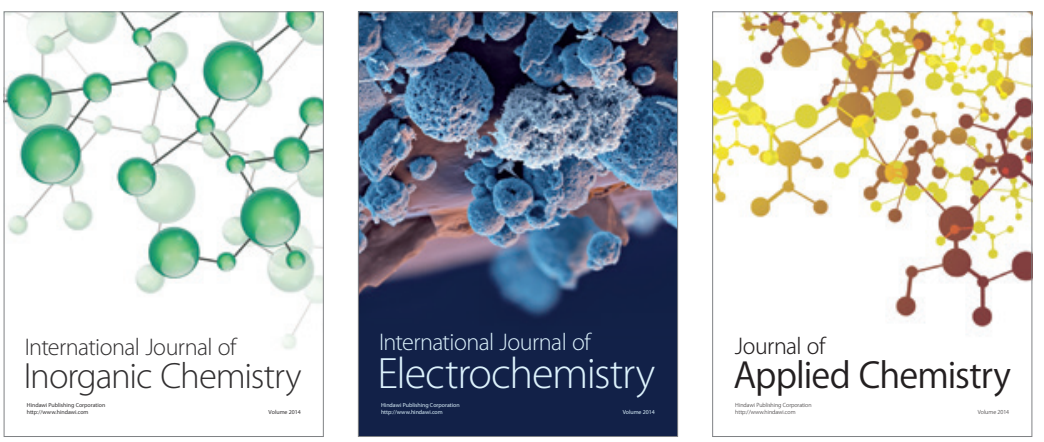

Journal of

Applied Chemistry
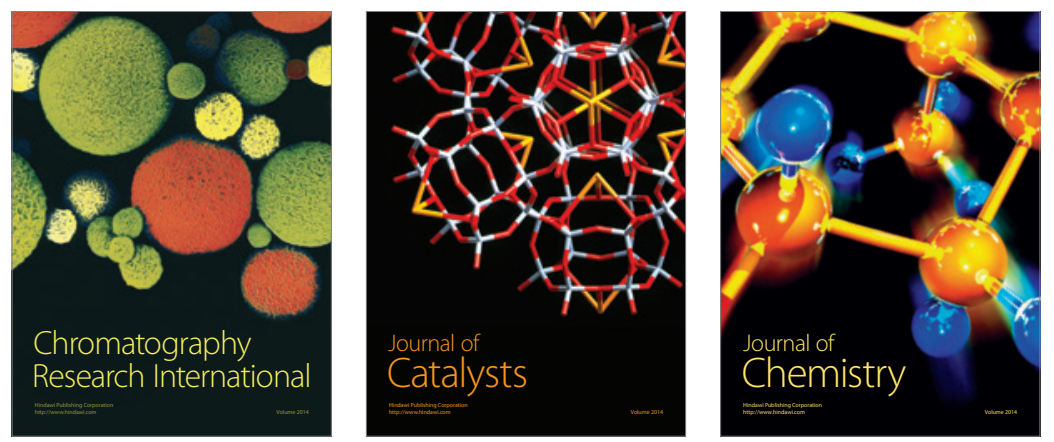
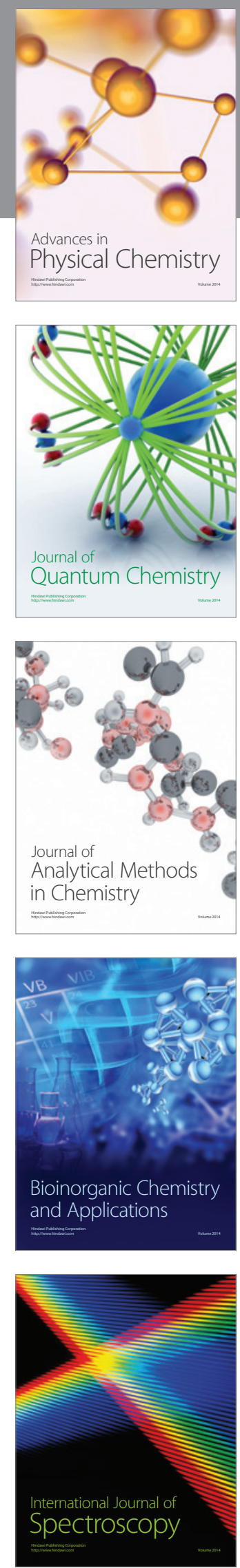